\author{
E. Di Gristina, P. Pedone, F. M. Raimondo
}

\title{
Plant landscape and phytodiversity in the ancient town of Erice (NW Sicily)
}

Di Gristina, E., Pedone, P. \& Raimondo, F. M.: Plant landscape and phytodiversity in the ancient town of Erice (NW Sicily). — Bocc. 28: 329-330. 2019. — ISSN: 1120-4060 printed, 2280-3882 online.

Key words: native flora, ornamental flora, biodiversity.

The town of Erice, in the province of Trapani, is an environmental unicum in the context of the ancient settlements of western Sicily. Its history, substrates, and particular climate, generated by its geo-orographic position, make it a particular hot spot of natural and cultural biodiversity. Located on the top of Mount San Giuliano, in addition to natural habitats with their specific florulas, the town shows small gardens and among the few inhabitants there is a widespread green culture. A tourist destination by its various architectural and landscape historical peculiarities, Erice presents a residential center made up by small stone buildings, with small courtyards or "bagli" often used to house pergolas, decorative or fruit plants placed in pots or in the ground. Protected from the wind - thanks to the special microclimatic conditions that occur at the top of the relief exposed to moist sea breezethey find the optimal environment to grow and preserve.

The Giardino del Balio, Villa Pepoli and the remains of the park around the town, as well as the Castello di Venere and the various rocky relieves within the town, the old walls of protection of the city, are ideal habitats for many native and cultivated species. Among the former we remember the endemic and very rare Centaurea erycina, Silene nefelites, and Brassica villosa subsp. drepanensis Other endemic species find the best habitat in emerging cliffs and in architectural artefacts; they are Silene fruticosa, Dianthus rupicola subsp. rupicola, Seseli bocconei, etc. In the same contexts other chasmophytes are also frequent among which Athamantha sicula emerges. On the margin of Villa Pepoli, awesome trees of Prunus mahaleb subsp. mahaleb testify to the ancient settlement of native tree species - rare on the island - then locally cultivated. In the Giardino del Balio, in addition to the ancient borders of Buxus sempervirens, luxuriant specimens of B. balearica remarks the sub-oceanic character of the climate at the top of Mt. San Giuliano. The presence of a rich contingent of pteri- 
dophytes and bryophytes also depends on such climate, including the rare epiphytic moss Cryphaea heteromalla, common right on the branches of the two Buxus species.

Addresses ofthe authors:

Emilio Di Gristina ${ }^{1}$, Pietro Pedone ${ }^{2} \&$ Francesco M. Raimondo ${ }^{3}$,

${ }^{1}$ Department of Agricultural, Food and Forest Sciences, University of Palermo,

Viale delle Scienze, Bldg. 4, 90128 Palermo, Italy. E-mail:

emilio.digristina@unipa.it

${ }^{2}$ Municipality of Erice, Trapani, Italy.

${ }^{3}$ PLANTA/Mediterranean and Tropical Center for Research, Documentation and

Training, Piazza Cairoli 11, 90123, Palermo, Italy. 